\title{
Diaphragmatic Response to Inspiratory versus Expiratory Training in Patients with Chronic Obstructive Pulmonary Disease
}

\author{
AZZA A. ABD EL-HADY, Ph.D. ${ }^{1}$; BASANT H. ELREFAEY, Ph.D. ${ }^{1}$, ; \\ YOUSSEF M. AMIN SOLIMAN, M.D. ${ }^{3}$ and HEBA TULLAH E. AFIFI, M.Sc. ${ }^{\mathbf{1 , 4}}$ \\ The Department of Physical Therapy for Cardiovascular Respiratory Disorders \& Geriatrics, Faculty of Physical Therapy, \\ Cairo University , The Department of Medical Rehabilitation, Faculty of Applied Medical Sciences, King Khaled University, \\ Abha, Saudi Arabia ${ }^{2}$, The Department of Chest Diseases, Faculty of Medicine, Cairo University ${ }^{3}$ and \\ The Department of Physical Therapy for Cardiovascular Respiratory Disorders \& Geriatrics, Faculty of Physical Therapy, \\ Badr University in Cairo, Egypt ${ }^{4}$
}

\begin{abstract}
Background: Chronic Obstructive Pulmonary Disease (COPD) is characterized by air flow limitation and mucus hypersecreastion.

Aim of Study: The present study was conducted to investigate the efficacy of inspiratory muscle training versus expiratory muscle training on thickness fraction in patients with chronic obstructive pulmonary disease.

Material and Methods: Forty patients (men) with chronic obstructive pulmonary disease were included in this study, their age ranged from 40-50 years; they had Body Mass Index (BMI) ranged from 18.5-29.9 $\left(\mathrm{kg} / \mathrm{m}^{2}\right)$. Patients were selected from outpatient clinic Faculty of Medicine, Cairo University, They were assigned randomly into two equal groups: Group Expiratory Muscle Training (EMT) which received expiratory muscle training by Positive Expiratory Pressure device (PEP) in addition to routine physiotherapy program according to department protocol in form of, percussion, vibration, shaking and postural drainage. Group Inspiratory Muscle Training (IMT), whom received inspiratory muscle training by inspiratory trainer in addition to the same physical therapy program that applied in group (EMT), both groups received treatment program 3 times/week for 12 weeks. The variable that used on this study is diaphragmatic thickness fraction measured by ultrasonography, was assessed before and after treatment program in both groups.
\end{abstract}

Results: The results revealed that there was no-significan improvement in diaphragmatic thickness fraction in two groups after twelve successive weeks, also revealed no significant difference when compared the two groups after treatment.

Conclusion: Within the limitation of the present study it could be concluded that EMT and IMT results in nonsignificant improvement in diaphragmatic thickness fraction.

Key Words: Diaphragm-Fraction thickness - Inspiratory training - Expiratory training - Chronic obstructive pulmonary disease.

Correspondence to: Dr. Heba Tullah E. Afifi, E-Mail: hebaemad2005@hotmail.com

\section{Introduction}

GLOBAL Initiative for Chronic Obstructive Lung Disease (GOLD) defined COPD in more generalized acceptance: "COPD is a disease state characterized by airflow limitation that is not fully reversible", the airflow limitation is usually both progressive and associated with an abnormal inflammatory response of the lungs to noxious particles or gases [1]

The real prevalence is masked by the burden of un diagnosed COPD when the British Lung Foundation found that the prevalence of COPD is $10.2 \%$ (4.4\% having GOLD II or worse) and only a quarter having a prior diagnosis [2] .

The most disabling symptom of COPD is dyspnea, which primarily results from a decrease in the capacity of the respiratory muscles to meet an increased mechanical load, several mechanisms contribute to the imbalance between load and capacity and consequent respiratory muscle dysfunction, hyperinflation that associated with COPD patients decreases the resting length of the diaphragm and, less so, of the rib cage muscles [3].

Shortening in diaphragm that associated with COPD was entirely due to a decrease in the length of the zone of apposition, which causes a decrease in the pressure generated by the diaphragm, the zone of apposition normally constitutes $60 \%$ of the diaphragm's total area, but only $40 \%$ in patients with COPD [4] .

The majority of studies dealing with factors contributing to respiratory muscle dysfunction in 
COPD have focused mainly on the diaphragm, because it is the principle muscle of respiration [5].

Pulmonary rehabilitation is an important component in the management of COPD. It has been shown to improve exercise capacity and health related quality of life, and to reduce breathlessness, anxiety or depression, and the frequency and length of hospitalizations related to COPD [6].

Training of the inspiratory muscles is one component of a pulmonary rehabilitation program that can be applied in either combination with physical exercise, or as an independent intervention. IMT (inspiratory muscle training) has a growing evidence base to support its efficacy as a method of improving breathlessness, exercise tolerance and quality of life, it offers a lifeline to many patientsfor whom pharmacological treatment options have been exhausted [7].

Expiratory muscle training improves functional exercise capacity and decreased dyspnea during daily living activities ,resulting in a better health related quality of life in patients with severe COPD [8].

\section{Subjects and Methods}

\section{I- Subjects:}

The study was conducted at the out-patient clinic, Faculty of Medicine, Cairo University at the period between September 2018 and September 2019 , patient referred by chest physician.

Forty patients (men) with mild to moderate chronic obstructive pulmonary disease (class I-II) according to (GOLD 2019) classification were included in this study, their age ranged from 4050 years, they were assigned randomly into two equal groups (A (EMT) and B (IMT)).

- Group A (EMT): Who received expiratory muscle training by threshold PEP positive expiratory pressure device in addition to conventional chest physiotherapy about 30 minutes 3 times/week for twelve weeks.

- Group B (IMT): Who received inspiratory training by IMT device in addition to conventional physiotherapy (same program that applied in group EMT), 30 minutes 3 times/week for twelve weeks.

The participated patients were selected according to the following inclusion criteria: Their Body Mass Index (BMI) would be ranged from 18.5-
$29.9 \mathrm{Kg} / \mathrm{m}^{2}$, all patients would be diagnosed as mild to moderate chronic obstructive pulmonary disease (Class I-II) according to GOLD classification (FEV $150-80 \%$ predicted) with Smoking index $>400$ (chronic heavy smoker), all patients would be clinically and medically stable.

Those patients who were excluded from the study: Patients with chronic respiratory failure $\left(\mathrm{PaO}_{2}\right.$ lower than 60$)$, bronchial asthma, coronary artery disease, chronic metabolic diseases, recent abdominal or thoracic surgery, treatment with corticosteroids, hormones or chemotherapy, neurological disorders and increased intracranial pressure.

\section{II- Material and Methods:}

\section{A- Evaluation instrumentation:}

1- Spirometer: Spirometer (Jeager-Master Screen Pulmonary Function Test (MS-PFT) analyzer unit made in Germany) was used to initially diagnose the patients as Chronic Obstructive Pulmonary Disease (COPD).

For measurement of Forced Vital Capacity (FVC) and forced expiratory volume in $1 \mathrm{sec}$ (FEV 1), the patient was instructed to do 3 normal quite breathing (tidal volume) then the patient takes a deep breath in, as large as possible, and blows out as hard and as fast as possible and keeps going until there is no air left (as they blowing a candle) [9].

2- Ultrasonography: Portable unite ultrasonography (Hitachi EUB-7000 made in Japan) used to evaluate the diaphragmatic fraction of thickness before and after treatment for both groups. Changes of diaphragm thickness were studied by B mode (two dimensional) ultrasound, Probe held perpendicular to the chest wall in the line of a right intercostal space between the anterior axillary and mid axillary lines to observe the diaphragm in the zone of apposition 1-2cm below the costophrenic angle, the changes of thickness were observed at end of resting expiration (functional residual capacity level) and at end of deep inspiration (total lung capacity level), the patient should have a supine lying position, turning off his clothes to be in a relaxed position, fraction thickness calculated as follow: Inspiratory thickness-expiratory thickness/ expiratory thickness [10].

\section{B- Treatment measurement:}

For Group A (EMT): Received expiratory muscle training using expiratory muscle trainer, about 30 minutes 3 times/week for twelve weeks, in 
addition to conventional physical therapy program was applied in form of the following: Postural drainage: It is important to clear mucus through specific positions that used the gravity to drain segment's secretions so that emphasize the expansion of the segments, percussion, vibration, shaking: Done to help break up secretions.

For group B (IMT): This group received the same physical therapy program that applied in group $\mathrm{A}$ in addition to inspiratory muscle training using inspiratory muscle trainer 3 times/week for twelve weeks.

Expiratory muscle trainer: (Model REF-HS730, Threshold ${ }^{\circledR}$ PEP Philips-Respironic, USA) is designed to strength expiratory muscles through the use of resistance during expiratory effort. Threshold PEP incorporates a flow-independent one-way valve to ensure consistent resistance with adjustable specific pressure settings (in $\mathrm{cm} \mathrm{H}_{2} \mathrm{O}$ ), it can be graded from 5 to $20 \mathrm{~cm} \mathrm{H}_{2} \mathrm{O}$. Made of durable, high-impact acrylic, contains a spring-loaded valve at one end and a mouthpiece on the other, the valve blocks air flow until the patient generates sufficient expiratory pressure to overcome the resistance provided by the spring-loaded valve, when patients exhale through threshold PEP, the resistive load creates positive pressure that helps open the airways and allows mucus to be expelled during "huff" coughing (forced expiratory technique) [11]

Inspiratory muscle trainer: (Model REF-HS730, Threshold ${ }^{\circledR}$ IMT Philips-Respironic, USA) is used as inspiratory muscle trainer, commercially available lightweight clear plastic cylinder (weight, $36.4 \mathrm{~g}$; diameter, $4.06 \mathrm{~cm}$ ) that contains a springloaded valve at one end and a mouthpiece on the other, the valve blocks air flow until the patient generates sufficient inspiratory pressure to overcome the resistance provided by the spring-loaded valve, the threshold pressure is independent of airflow rate or breathing frequency, this device is mainly used in patients with chronic obstructive pulmonary disease [12]

\section{Analysis of results:}

Sample size: The sample-size calculation showed that 40 subjects were needed in this study at an alpha level of 0.05 with $80 \%$ power and large effect size. Sample size calculation was performed prior to the study using G*POWER statistical software (version 3.1.9.2; Franz Faul, Universitat Kiel, Germany).

\section{Data analysis:}

All statistical analyses were performed using IBM SPSS statistical package version 25 for Windows (IBM SPSS, Chicago, IL, USA). Mean and standard deviation were calculated for descriptive statistics. Statistical significance was defined as $p$ $<0.05$. Subject characteristics were compared between groups using $t$-test. Shapiro-Wilk test was used to check the normal distribution of data and Levene's test for homogeneity of variances was conducted to test the homogeneity between groups. Within and between groups comparisons were carried through mixed design MANOVA. Post-hoc tests using the Bonferroni correction were carried out for subsequent multiple comparison.

\section{Results}

\section{Subject characteristics:}

Forty subjects were participated in this study. The mean \pm SD of the group A (EMT) was $46.05 \pm$ 3.13 and that of group B (IMT) was $45.5 \pm 3.51$. There was no significant difference in the mean age between both groups $(p=0.6)$.

\section{Effect of treatment on thickness fraction:}

Mixed MANOVA revealed that there was no significant interaction of treatment and time (Wilks' Lambda $=0.98 ; \mathrm{F}(4,35)=0.15, p=0.96)$, there was a significant main effect of time (Wilks' Lambda $=0.04 ; \mathrm{F}(4,35)=176.38, p=0.001)$, there was no significant main effect of treatment (Wilks' Lambda $=0.94 ; \mathrm{F}(4,35)=0.54, p=0.7)($ Table 1$)$ showed descriptive statistics of thickness fraction as well as the significant level of comparison between groups and the significant level of comparison between pre and post-treatment in each group.

Table (1): Mean thickness fraction pre and post-treatment of group A (EMT) and B (IMT).

\begin{tabular}{|c|c|c|c|c|c|c|c|c|}
\hline & \multicolumn{2}{|c|}{ Pre-treatment } & \multirow{2}{*}{$\begin{array}{c}p- \\
\text { value }\end{array}$} & \multicolumn{2}{|c|}{ Post-treatment } & \multirow{2}{*}{$\begin{array}{c}p- \\
\text { value }\end{array}$} & \multirow{2}{*}{$\begin{array}{c}\text { Repeated } \\
\text { measures } \\
\text { (Group } \\
\text { EMT) }\end{array}$} & \multirow{2}{*}{$\begin{array}{c}\text { Repeated } \\
\text { measures } \\
\text { (Group } \\
\text { IMT) }\end{array}$} \\
\hline & $\begin{array}{c}\text { Group EMT } \\
\mathrm{X} \pm \mathrm{SD}\end{array}$ & $\begin{array}{l}\text { Group IMT } \\
\quad x \pm S D\end{array}$ & & $\begin{array}{l}\text { Group EMT } \\
X \pm S D\end{array}$ & $\begin{array}{l}\text { Group IMT } \\
\mathrm{X} \pm \mathrm{SD}\end{array}$ & & & \\
\hline Thickness fraction (\%) & $113.47 \pm 38.82$ & $109.3 \pm 33.31$ & 0.71 & $107.17 \pm 36.77$ & $105.56 \pm 30.77$ & 0.88 & 0.11 & 0.33 \\
\hline
\end{tabular}




\section{Within group comparison:}

Both groups showed that was no significant change in thickness fraction of both groups posttreatment $(p>0.05)$ (Table 1) Figs. $(1,2)$

\section{Between groups comparison:}

There was no significant difference thickness fraction between both groups pre-treatment ( $p$ $>0.05$ ). Comparison between groups post-treatment revealed non significant difference in thickness fraction between groups post-treatment $(p>0.05)$. (Table 1) Fig. (3).

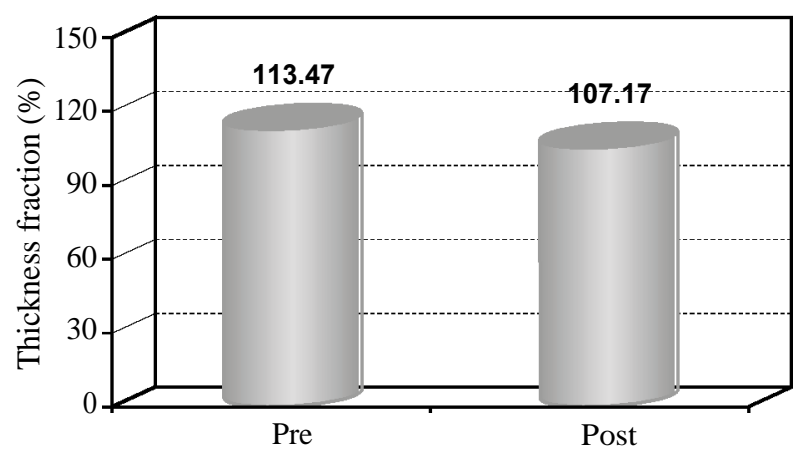

Fig. (1): Pre and post-treatment mean values of thickness fraction of the group A (EMT) with percent of improvement $5.55 \%$.

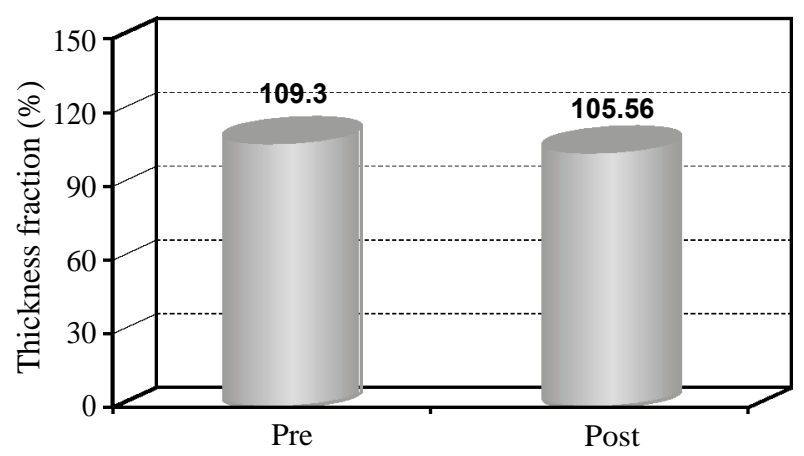

Fig. (2): Pre and post-treatment mean values of thickness fraction of the group B (IMT) with percent of improvement $3.42 \%$.

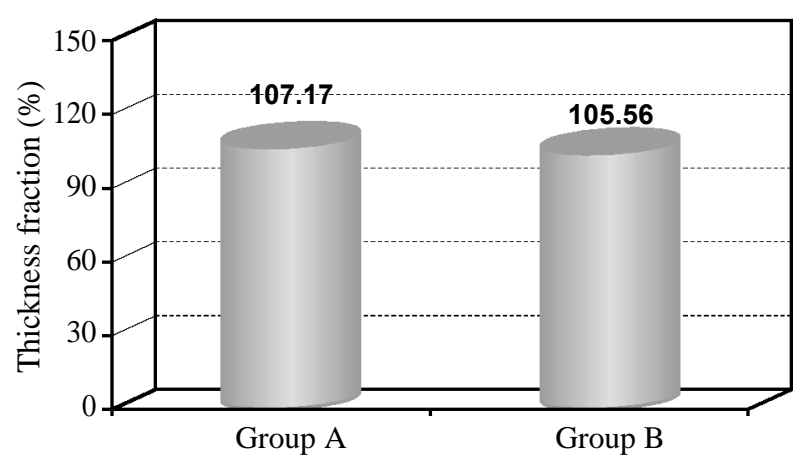

Fig. (3): Post-treatment mean values of thickness fraction of group A (EMT) and B (IMT) with percent of improvement $1.61 \%$.

\section{Discussion}

The present work was essentially planned to investigate the efficacy of inspiratory muscle training versus expiratory muscle training on diaphragm in patients with chronic obstructive pulmonary disease measured by thickness fraction.

The current study was applied as the process of rehabilitation of COPD patients is an important clinical problem. In the near past, the implementation of COPD management programs aimed to overcome symptoms and lifestyle modifications to improve health status and reduce hospital admission [13]. So, this study was conducted in an effort for successful establishing of a rehabilitation program which could be beneficial for COPD patients.

Also, the selection of the patients with COPD in the present study was supported by Dos Santos Yamaguti, et al., [14] who said that, patients with COPD were characterized by impaired diaphragmatic mobility when compared with healthy, age matched individuals. In addition, some patients with COPD have significant involvement of the lung parenchyma and yet retain their diaphragm mobility. A number of pathophysiological mechanisms of COPD, such as airway obstruction, pulmonary hyperinflation and air trapping, might be involved in this process of impairment of diaphragmatic function. However, the reduction in diaphragm mobility in COPD patients is mainly due to air trapping and is not influenced by respiratory muscle strength or pulmonary hyperinflation so in COPD patient we have to improve diaphragmatic mobility rather than diaphragmatic strength.

Choosing thickness fraction was accepted with Iwasawa, et al., [15] who said that, diaphragmatic thickness fraction measurements have been reported to be a potential tool for the assessment of disease status and outcomes in patients with COPD. Some authors who examined inspiratory muscular dysfunction in COPD, the main focus of interest was the diaphragmatic muscle, because the diaphragm is not only the major inspiratory muscle, but also represents the muscular structure that is most intensely affected by hyperinflation.

The previous results comes in agreement with a Eryüksel, et al., [16] who mentioned that, diaphragmatic thickness fraction measurements based on diaphragmatic ultrasound assessment in subjects with COPD seemed to be unable to identify subjects at high risk of symptoms and exacerbations as defined by the Global Initiative for Chronic Obstructive Lung Disease. 
Also, the findings of this study revealed that the diaphragmatic dysfunction associated with COPD patients doesn't concerning it's fraction of thickness which agreed with Levine, et al., [17], Similowski, et al., [18] who revealed that an increased mechanical load on the diaphragm because of airway obstruction, diaphragmatic myofibrils exhibit an increased level of activity against an increased mechanical load, and undergo structural remodeling and chronic adaptation that lead to a chronic endurance training-type effect on the diaphragmatic muscle.

On the other hand there is a study used inspiratory muscle training for patients with chronic obstructive pulmonary disease, using initial training load equivalent to at least $30 \%$ of person's maximum inspiratory pressure, 3 times a week for 8 weeks, with load progressively increased as symptoms permit increased inspiratory muscle strength and improvement in dyspnea and exercise capacity [19].

Similarly, another study concluded that IMT improves inspiratory muscle strength and endurance, functional exercise capacity, dyspnea and quality of life. Inspiratory muscle endurance training was shown to be less effective than respiratory muscle strength training. In patients with inspiratory muscle weakness, the addition of IMT to a general exercise training program improved PImax and tended to improve exercise performance [20]

There is still debate as regards to which is the mechanism responsible for the enhanced inspiratory muscle force following IMT, some authors argue that inspiratory muscles of COPD patients are already well adapted to chronic loading and do not express any adaptation in response to training. Nonetheless, a substantial increase in the proportion of type I fibers of the external intercostal muscles have been found after IMT [21] .

Concerning expiratory training there is much less data related to expiratory muscles in COPD, impairment in abdominal muscles and internal intercostal muscles significant in COPD patients but they have been little studied, as evidenced by either mild reduction inn maximal force and/or endurance [21]

When Suzuki, et al., [22] studied the effect of specific expiratory training in healthy individuals, they were able to provide evidence of improved strength and reduced sensation of respiratory effort.

To sum up, inspiratory and expiratory training are vital parts in treatment of COPD patients. So, more studies are needed to clarify the effect of inspiratory versus expiratory training on diaphragmatic fraction thickness.

\section{Conclusion:}

This study concluded that adding both inspiratory and expiratory muscle training to rehabilitation program of chronic obstructive pulmonary disease has non-significant effect on diaphragmatic fraction of thickness.

\section{References}

1- SINGH D., AGUSTI A., ANZUETO A., BARNES P.J., BOURBEAU J., CELLI B.R. and VARELA M.V.L.: Global strategy for the diagnosis, management, and prevention of chronic obstructive lung disease: The GOLD science committee report 2019. European Respiratory Journal, 53 (5): 1900164, 2019.

2- PARRILLO J.E. and DELLINGER R.P.: Critical care medicine e-book: Principles of diagnosis and management in the adult. Elsevier Health Sciences, 2013.

3- DAHER A., MATTHES M., KESZEI A., BRANDENBURG V., MÜLLER T., CORNELISSEN C. and DREHER M.: Characterization and Triggers of Dyspnea in Patients with Chronic Obstructive Pulmonary Disease or Chronic Heart Failure: Effects of Weather and Environment. Lung, 197 (1): 21-8, 2019.

4- HELLEBRANDOVÁ L., CHLUMSKY J., VOSTATEK P., NOVÁK D., R'YZNAROVÁ Z. and BUNC V.: Airflow limitation is accompanied by diaphragm dysfunction. Physiological research, 65 (3), 2016.

5- OTTENHEIJM C.A., HEUNKS L.M., SIECK G.C., ZHAN W.Z., JANSEN S.M., DEGENS H., De BOO T. and DEKHUIJZEN P.R.: Diaphragm dysfunction in chronic obstructive pulmonary disease. American Journal of Respiratory and Critical Care Medicine, 172 (2): pp. 2005,2005 .

6- McCARTHY B., CASEY D., DEVANE D., MURPHY K., MURPHY E. and LACASSE Y.: Pulmonary rehabilitation for chronic obstructive pulmonary disease. Cochrane Database of Systematic Reviews, (2). Pneumologia, 34 (12): 1008-18, 2015.

7- McCONNELL A.K.: The role of inspiratory muscle function and training in the genesis of dyspnoea in asthma and COPD. Primary Care Respiratory Journal, 14 (4): $186,2005$.

8- MOTA S., GÜELL R., BARREIRO E., SOLANES I., RAMÍREZ-SARMIENTO A., OROZCO-LEVI M. and SANCHIS J.: Clinical outcomes of expiratory muscle training in severe COPD patients. Respiratory Medicine, 101 (3): 516-24, 2007.

9- WANGER J., CLAUSEN J.L., COATES A., PEDERSEN O.F., BRUSASCO V., BURGOS F. and GUSTAFSSON P.: Standardisation of the measurement of lung volumes. European respiratory journal, 26 (3): 511-22, 2005.

10- UMBRELLO M. and FORMENTI P.: Ultrasonographic assessment of diaphragm function in critically ill subjects. Respiratory Care, 61 (4): 542-55, 2016. 
11- TOUT R., TAYARA L. and HALIMI M.: The effects of respiratory muscle training on improvement of the internal and external thoraco-pulmonary respiratory mechanism in COPD patients. Ann. Phys. Rehabi. Med., 56: $193-$ $211,2013$.

12- MENZES K.K.P., NASCIMENTO L.R., AVELINO P.R., POLESE J.C. and SALMELA L.F.T.: A Review on Respiratory Muscle Training Devices. J. Pulm. Respir. Med., 8 (451): 2, 2018.

13- BOURBEAU J., NAULT D. and DANG-TAN T.: Selfmanagement and behavior modification in COPD. Patient Educ. Couns., 52: 271-7, 2004.

14- DOS SANTOS YAMAGUTI W.P., PAULIN E., SHIBAO S., CHAMMAS M.C., SALGE J.M., RIBEIRO M. and CARVALHO C.R.F.: Air trapping: The major factor limiting diaphragm mobility in chronic obstructive pulmonary disease patients. Respirology, 13 (1): 138-44, 2008.

15-IWASAWA T., TAKAHASHI H., OGURA T., ASAKURA A., GOTOH T., SHIBATA H. and INOUE T.: Influence of the distribution of emphysema on diaphragmatic motion in patients with chronic obstructive pulmonary disease. Japanese journal of radiology, 29 (4): 256-64, 2011.

16- ERYÜKSEL E., CIM SIT C., BEKIR M., CIMSIT Ç. and KARAKURT S.: Diaphragmatic thickness fraction in subjects at high-risk for COPD exacerbations. Respiratory Care, 62 (12): 1565-70, 2017.
17- LEVINE S., NGUYEN T., KAISER L.R. and SHRAGER J.B.: Evaluating respiratory muscle adaptations: A new approach, 2002

18- SIMILOWSKI T., YAN S., GAUTHIER A.P., MACKLEM P.T. and BELLEMARE F.: Contractile properties of the human diaphragm during chronic hyperinflation. New England Journal of Medicine, 325 (13): 917-23, 1991.

19-HILL K., CECINS N.M., EASTWOOD P.R. and JENKINS S.C.: Inspiratory muscle training for patients with chronic obstructive pulmonary disease: A practical guide for clinicians. Archives of physical medicine and rehabilitation, 91 (9): 1466-70, 2010.

20- GOSSELINK R., De VOS J., VAN DEN HEUVEL S.P., SEGERS J., DECRAMER M. and KWAKKEL G.: Impact of inspiratory muscle training in patients with COPD: what is the evidence? European Respiratory Journal, 37 (2): 416-25, 2011.

21- RAMIREZ-SARMIENTO A., OROZCO-LEVI M., BARREIRO E., MÉNDEZ R., FERRER A., BROQUETAS J. and GEA J.: Expiratory muscle endurance in chronic obstructive pulmonary disease. Thorax, 57 (2): 132-6, 2002.

22- SUZUKI S., SATO M. and OKUBO T.: Expiratory muscle training and sensation of respiratory effort during exercise in normal subjects. Thorax, 50 (4): 366-70, 1995.

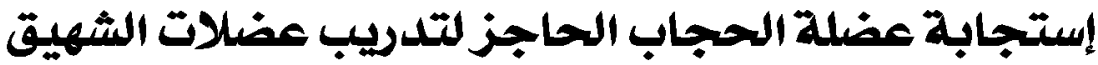 مقابل عضلات الزفير في مرضى الإنسداد الرئوى المزمن
}

\author{
الخلفية: يتميز مرض الإنسداد الرئوى المزمن بصعوبة تدفق الهواءوفرط نشاط المخاط. \\ الهدف من الدراسة: آجريت هذه الدراسة لمعرفة مدى فعالية تدريب عضلات الشهيق مقابل التريب على عضلات الزفير على نسبة سمك

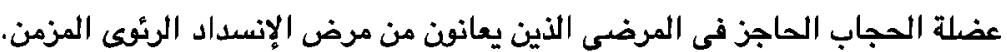

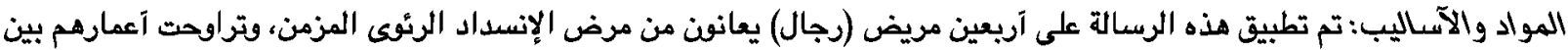

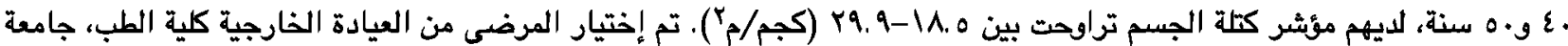

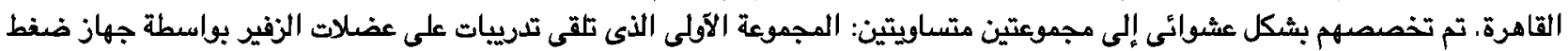

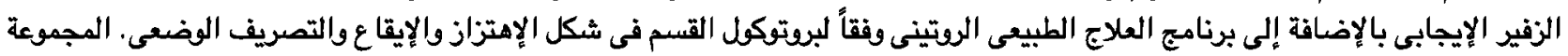

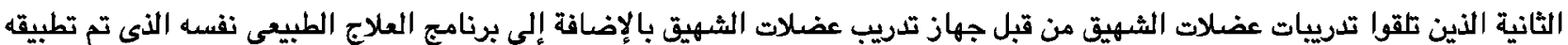

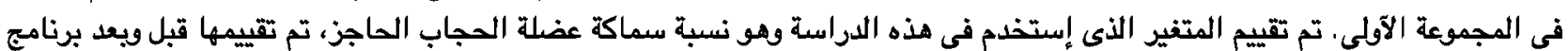

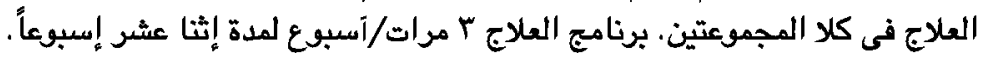 \\ النتائج: آظهرت النتائج آنه لم يكن هناك تحسن كبير فى نسبة سمك عضلة الحجاب الحاجز في مجموعتين بعد إثنى عشر إسبوعاً متتالياً، \\ كما لم تظهر آى فرق كبير عند مقارنة المجموعتين بعد العلاج. \\ الخلاصة: فى حدود هذه الدراسة، يمكن آن نستتج آن تدريب عضلات الشهيق مقابل تدريب عضلات الزفير ينتج عنها تحسن ليس له دلالة \\ إحصائية في نسبة السماكة لعضلة الحجاب الحاجز العزان.
}

